\title{
GEREJA MEMPERHATIKAN ORANG MISKIN SEBAGAI REVELASI DAN KONTEMPLASI SUBSTANSI \\ EVANGELIUM: \\ REFLEKSI KRISTIS ATAS DOKUMEN EVANGELII GAUDIUM
}

\author{
Heribertus Susanto Wibowo
}

\begin{abstract}
The Church itself is a sacrament or a mystery. Her life and development are inspired by the Holy Spirit. The Church herself has a fundamental mission to proclaim evangelization and the kingdom of God. God, who reigns, has a preferential option for the poor. God has a special heart for the poor as well. It is great, so God, which incarnate in Jesus - The Gospel - Evangelium - lives a reality in the way of the poor. The Church is constantly called to have attention to the poor and account them. In this way, the Church encounters her Lord, whom reveals Himself within the poor. The poor, then, became lord and master. For they have taught the Church find the quality of the values. It comes from God which signed by love, solidarity and compassion. Serving and having attention to the poor are in fact a spiritual direction to contemplate Jesus the Lord. There, the Church and the world at large, eventually, will find a redemption and transformation of the living, and find the joy of the Gospel as well.
\end{abstract}

Keywords: The Church, the poor, evangelium, contemplate, reveal, have attention, spiritual

direction, love, solidarity, compassion, joy.

Paus Fransiskus, melalui Evangelii Gaudium, menyatakan: "model saat ini yang menekankan keberhasilan dan hak pribadi, tidak tampak mendukung investasi dalam upaya-upaya membantu mereka yang tertinggal, yang lemah atau yang kurang berbakat untuk dapat menemukan peluang-peluang dalam hidup" $(E G, 209)$. Namun, "Yesus, Sang penginjil yang amat hebat dan Injil yang mempribadi, manyamakan Diri terutama dengan mereka yang hina (bdk. Mat 25:40). Hal ini mengingatkan kita umat Kristiani bahwa kita dipanggil untuk memperhatikan mereka yang lemah di bumi” (EG, 209).

Dalam Desus Caritas Est, Paus Benediktus XVI mempertegas pemakluman karya Gereja "memperhatikan orang miskin merupakan karya karitatif Gereja yang tidak bisa diserahkan kepada pihak lain manapun. Kerena karya kepada orang miskin itu adalah ungkapan jati dirinya yang perlu" $(D C, 25)$.

jsh Jurnal Sosial Humaniora, Vol 8 No.1, Juni 2015 
Paus Yohanes Paulus II, dalam Sollicitudo Rei Socialis (SRS), mengatakan: "Dalam dunia yang terbagi menjadi kaya dan miskin serta penindas dan yang tertindas ini, pewartaan tentang Kerajaan Allah sebagai komunitas keadilan dan persaudaraan menghimbau adanya sikap untuk berpihak pada kaum miskin" (SRS, 42).

Pilihan Gereja memperhatikan orang miskin ini dijalankan bukan hanya karena belas kasih atau ideologi perjuangan kelas tetapi merupakan pilihan spiritualitas yang dilakukan dalam usaha mengikuti hidup Yesus yang telah menyatakan diri-Nya dengan kaum miskin dan papa (bdk. Flp 2:5-8). Semangat dasar Evangelii Gaudium lebih membawa Gereja menemukan kepenuhan sukacita dalam karyanya memperhatikan orang miskin. Sukacita murid-murid Kristus adalah menjumpai Tuhan $(E G, 1)$. Pada orang miskin, hati-Nya memiliki tempat yang khusus. Sampai Ia sendiri “menjadi miskin” (2 Kor 8:9; bdk. EG, 197).

Istilah 'revelasi' merupakan sebuah diksi yang sangat penting (bdk.Wehmeier, ed., Oxford Advanced, 2000:1140), lebih lagi bila diksi 'revelasi' itu dipakai dalam kasanah refleksi teologis. Revelasi menunjuk kepada dimensi ilahi. Revelasi adalah sebuah penyingkapan diri Allah (bdk. O’Collins, Kamus Teologi, 1996:350). Dalam perjanjian Baru, Allah merevelasi Diri-Nya dalam diri Sang Putra $(D V, 4 ; 17)$. Allah juga dikenal lewat tanda pelayanan kasih yang dilakukan jemaat Kristiani (bdk. $D C, 24)$

Berkenaan dengan penyingkapan Allah, ada tiga realitas yang menunjuk kepadanya. Hal tersebut sangatlah substansial, karena ia berkenaan dengan revelasi diri Allah. Pertama, Gereja adalah sakramen Yesus Kristus $(G S, 1)$. Gereja, juga, dideklarasikan oleh Paus Paulus VI sebagai sebuah misteri. "The Church is a mystery. It is a reality imbued with the hidden presence of God" (lih. McBrien, The Church, 2008:1). Kedua, kaum miskin merupakan representasi diri Allah (EG, 197). Kehadiran dan karya Allah secara istimewa dinyatakan dalam diri orang miskin (Gerald, Kamus Teologi, 1996:200). Dalam kasanah teologi biblis, kaum miskin sering juga disebut sebagai masyarakat kontras (bdk. Darmawijaya, Keterlibatan, 1991:63). Ketiga, hal yang berkaitan dengan kata Evangelium itu sendiri. 
Evangelium merujuk kepada Yesus. Dialah Penyelamat sejati (bdk. Ratzinger, Yesus, 2010:46).

Tulisan ini memaparkan mengenai Gereja terus memperhatikan orang miskin. Karya kepedulian terhadap mereka yang lemah dan terlantar sepertinya tak ada habisnya hingga akhir waktu. Berbagai alasan kepedulian dijabarkan termasuk spiritualitas yang mendasarinya. Karya karitatif kepada orang miskin bukan hanya karya yang tidak bisa diwakilkan kepada pihak lain manapun; bukan pula sekedar ungkapan jati diri Gereja yang perlu. Namun secara lebih mendasar; sesungguhnya ia mengandung substansi yang selalu ditemukan dari karya Gereja memperhatikan orang miskin itu.

\section{Kepedulian Terhadap Yang Lemah}

Pelibatan kaum miskin dalam masyarakat adalah sikap Gereja menanggapi persoalan besar kemanusiaan, yang dilihat oleh Paus Fransiskus sebagai soal mendasar, pada saat ini dalam sejarah. (bdk. EG, 185). Dan hal ini akan menentukan masa depan kemanusiaan. Paus Fransiskus, dalam hal ini, memperlihatkan bahwa Gereja senantiasa berusaha memperhatikan orang miskin (bdk. EG, 187).

Paus Fransiskus melihat bahwa zaman semakin menjunjung keberhasilan dan pengangkatan diri. Orang-orang miskin kian menjadi masyarakat manusia yang dikesampingkan. Gereja, dalam situasi ini, memusatkan perhatiannya justru kepada orang miskin. Gereja memperhitungkan mereka agar terlibat juga kedalam realitas jalinan persahabatan dan persaudaraan sebagai sesama manusia. Karena orang miskin pun adalah bagian utuh dari realitas sosial masyarakat manusia (bdk. $E G, 185)$.

Kepedulian Gereja kepada orang miskin membangun dasarnya dalam iman akan Kristus, yang menjadi miskin, dan selalu dekat dengan kaum miskin dan kaum tersingkir (bdk. EG,186). 


\section{Kesetiaan kepada Injil}

Perintah mendengarkan jeritan kaum miskin mendarah daging dalam diri kita bilamana kita sangat tersentuh oleh penderitaan orang-orang lain. Dengarkanlah apa yang diajarkan oleh Sabda Allah kepada kita tentang kemurahan hati, dan membiarkan Sabda itu menggema dalam hidup Gereja. Injil mengatakan kepada kita: "Berbahagialah orang yang murah hatinya, karena mereka akan beroleh kemurahan" (Mat 5:7).

Rasul Yakobus mengajarkan bahwa belas kasih kita kepada sesama akan membebaskan kita pada hari penghakiman Allah: "Berkatalah dan berlakulah seperti orang-orang yang akan dihakimi oleh hukum yang memerdekakan orang. Sebab penghakiman yang tidak berbelas kasihan akan berlaku atas orang yang tidak berbelas kasihan. Akan tetapi, belas kasihan akan menang atas penghakiman" (Yak. 2:12-13). Dalam kutipan ini Yakobus setia pada tradisi sangat kaya dari spiritualitas Yahudi pasca-pembuangan, yang mengaitkan belas kasih dengan nilai penyelamatan yang istimewa: "Lepaskanlah diri tuanku dari dosa dengan melakukan keadilan, dan dari kesalahan dengan menunjukkan belas kasih terhadap orang yang tertindas; dengan demikian kebahagiaan tuanku akan dilanjutkan!" (Dan 4:27; Bdk EG, 193).

Pesan ini sangat jelas dan langsung, begitu sederhana dan fasih, sehingga tak ada penafsiran gerejawi berhak untuk menisbikannya. Paus Fransiskus, kemudian menegaskan: Refleksi terhadap teks-teks ini jangan sampai mengaburkan atau melemahkan daya kekuatannya, tetapi mendorong kita untuk menerima seruannya dengan keberanian dan semangat.

Seruan Kitab Suci memerintahkan kita dengan tegas untuk melaksanakan kasih persaudaraan, untuk melayani dengan rendah hati dan murah hati, untuk berlaku adil serta berbelaskasih kepada kaum miskin. Yesus telah mengajari kita jalan pengakuan terhadap orang-orang lain dengan kata-kata dan tindakan-tindakanNya $(E G, 194)$.

Ketika Santo Paulus menemui para rasul di Yerusalem untuk mempertimbangkan apakah ia "sedang berusaha atau telah berusaha dengan percuma' (Gal 2:2), kriteria utama keaslian yang mereka sampaikan adalah bahwa ia tidak boleh melupakan orang-orang miskin (bdk. Gal 2:10; EG, 195). Kita mungkin 
tidak selalu dapat merefleksikan dengan tepat keindahan Injil, tetapi ada satu tanda yang selalu harus kita nyatakan: pilihan pada mereka yang terkecil, mereka yang dibuang dan dipinggirkan oleh masyarakat $(E G, 195)$.

\section{Tempat Khusus Kaum Miskin di dalam Umat Allah}

Hati Allah memiliki tempat khusus bagi kaum miskin, sedemikian besarnya sehingga Ia sendiri "menjadi miskin" (2 Kor 8:9). Seluruh sejarah keselamatan kita ditandai oleh kehadiran orang-orang miskin. Keselamatan datang kepada kita dari "ya" yang diucapkan oleh seorang gadis kalangan bawah dari kampung kecil di pinggiran sebuah kerajaan besar. Penyelamat lahir di sebuah palungan, di tengahtengah hewan-hewan, seperti anak-anak dari keluarga miskin; Dia telah dipersembahkan di Bait Allah dengan dua tekukur, persembahan orang-orang yang tidak mampu mempersembahkan domba (bdk. Luk 2:24; Im 5:7). Dia dibesarkan dalam sebuah rumah pekerja biasa dan melakukan pekerjaan tangan untuk mendapatkan nafkah-Nya. Ketika Dia mulai mewartakan Kerajaan Allah, kerumunan orang-orang yang dirampas hak-hak mereka mengikuti Dia, dan dengan demikian Ia mewujudkan apa yang telah disabdakan-Nya: "Roh Tuhan ada pada-Ku, oleh sebab Ia telah mengurapi Aku, untuk menyampaikan kabar baik kepada orangorang miskin" (Luk. 4:18). Dia meyakinkan mereka yang dibebani oleh kesusahan dan dihimpit oleh kemiskinan bahwa Allah memiliki tempat istimewa bagi mereka di hati-Nya: "Berbahagialah, hai kamu yang miskin, karena kamulah yang empunya Kerajaan Allah" (Luk. 6:20). Dia menyamakan diri-Nya dengan mereka: "Sebab ketika Aku lapar, kamu memberi Aku makan;" dan Dia mengajarkan bahwa belas kasih kepada mereka ini adalah kunci menuju surga $(E G, 197)$.

\section{Berpihak Kepada Orang Miskin: Pilihan Tuhan Bukan Pilihan Kita}

Seorang pastor dari serikat sabda Allah, John Fuellenbach, dalam karyanya Mewartakan Kerajaan Allah memberi uraian analitis dan refleksi teologis yang sangat bagus tentang pilihan sikap Gereja terhadap kaum miskin (bdk. Fuellenbach, Mewartakan, 2004:232-236). Bagi Gereja, keberpihakan pada orang-orang miskin adalah kategori teologis. Allah menunjukkan kepada kaum miskin kemurahan hati- 
Nya yang pertama (bdk. EG, 198). Dan dalam kesadaran kritis, kita menemukan bahwa pilihan untuk berpihak kepada orang miskin ini bukan pilihan kita atau pilihan para ahli teologi, tetapi pilihan Tuhan sendiri. Tuhan telah memutuskan untuk berpihak kepada mereka dan merekalah yang dipilih untuk menjadi perantara utama keselamatan. Tuhan tidak memperhitungkan orang-orang yang berkuasa, berpengaruh atau berilmu pengetahuan, tetapi Tuhan memperhatikan orang-orang yang tidak diperhitungkan orang.

Cerita dalam Kitab keluaran memuat catatan kunci tentang sifat Tuhan yang sebenarnya: peran serta-Nya dalam sejarah manusia diungkapkan dengan jelas:

Aku telah memperhatikan dengan sungguh kesengsaraan umat-Ku di Mesir, dan Aku telah mendengar seruan mereka yang disebabkan oleh pengaruhpengaruh mereka, ya, Aku mengetahui penderitaan mereka. Sebab itu, aku telah turun untuk melepaskan mereka dari tangan Mesir (Kel 3:7-9).

Tuhan kita adalah Tuhan yang mau mendengar, melihat dan yang mau memperhatikan sepenuhnya penderitaan umat-Nya. Tuhan kita adalah Tuhan yang selalu mau peduli dan mau mengantar kita kepada kebebasan. Namun. Tuhan tidak melakukan semua itu sendiri, tetapi Dia memilih Musa, salah seorang yang tertindas untuk menjadi perantara pembebasan itu. Aku akan mengutus engkau kepada Firaun untuk membawa umat Israel, bangsa-Ku keluar dari Mesir (Kel 3:10).

Salah satu hal yang paling penting sekarang dalam kehidupan religius adalah meletakkan seluruh strukturnya ke dalam suatu proses penyerapan di antara orangorang miskin - bukan untuk menolong orang miskin; orang miskin tahu bagaimana menolong diri mereka sendiri, dan dalam arti itu, mereka tidak membutuhkan kita. Lebih baik kita belajar tentang Allah dari mereka, tentang kehidupan, tentang keadilan melalui hidup bersama dengan mereka.

Sebagimana Boff melihatnya, di dalam pelbagai gerakan pembebasan dalam zaman kita, orang sampai pada kesadaran akan rencana Allah bagi manusia secara keseluruhan, di dalamnya Dia mengantar kita dari kungkungan kepada kebebasan; bila kita melibatkan diri kita di antara orang miskin. Orang miskin dipandang sebagai satu sakramen melaluinya Allah menyatakan diri-Nya. Di sini kita bertemu 
dengan tuntutan Allah sendiri akan solidaritas, identifikasi diri dengan, dan sikap yang adil terhadap orang yang tersisihkan. Jawaban terhadap tuntutan Allah ini dipahami sebagai historifikasi dari iman yang ingin mengikatkan diri pada Allah yang hadir dalam orang miskin. Keterlibatan iman dipandang sebagai persatuan dengan Kristus yang miskin dan keinginan yang mendalam untuk hanya hidup dan mengikuti-Nya. Inilah apa yang dimaksudkan Deklarasi Puebla yang berkata: Orang miskin juga mengevangelisasi Gereja. Perhatian akan orang miskin membuat kita lebih mudah menemukan Allah, mengerti Kitab Suci, dan memurnikan doa kita.

Menurut Norbert F. Lohfink dalam bukunya Option for the Poor, pilihan Tuhan untuk berpihak kepada kaum miskin seperti yang terungkap dalam cerita Keluaran mengisyaratkan pembentukan "masyarakat kontras" yakni bahwa Tuhan dengan perantaraan Musa dan kelompoknya membimbing umat-Nya keluar dari tanah Mesir untuk dibebaskan.

Lohfink selanjutnya melihat komunitas-komunitas basis sebagai bentuk perwujudan rencana Tuhan membentuk masyarakat baru sebagai wadah terjadinya transformasi sosial. Masyarakat baru ini menjalani hidup yang kontras dengan masyarakat sebelumnya. Kehidupan mereka dibangun berdasarkan kenangan akan Israel dan hidup Yesus. Jadi komunitas basis atau yang oleh para ahli teologi pembebasan disebut sebagai "Gereja kaum miskin" ini merupakan masyarakat baru yang muncul sebagai Gereja di antara orang miskin dan tertindas yang telah bebas. Anggota masyarakat baru ini diandaikan sebagai orang-orang yang menjadi murid Yesus dan menjalani hidup seperti Dia. Masyarakat baru ini termasuk orang-orang kudus dan para martir sebagai realitas harapan mereka yang telah mengambil sikap berpihak pada kaum miskin.

Jika Tuhan benar-benar ingin menyelamatkan dunia melalui sekelompok orang yang termasuk dalam masyarakat kontras ini maka kesetiaan menjadi pengikut Kristus merupakan kriteria pokok untuk menjadi anggota masyarakat kontras yang dicita-citakan.

Terpanggil untuk mengikuti hidup Yesus seperti hidup yang dijalani-Nya di dunia memang memerlukan keberanian untuk mengambil resiko. Dalam hal ini, kita 
membutuhkan spiritualitas yang menjiwai kesepakatan hati untuk berpihak kepada kaum miskin.

\section{Spiritualitas yang Dibutuhkan:}

\section{Dijiwai Roh Kudus}

Komitmen Gereja memperhatikan orang miskin tidak hanya terdiri dari kegiatan-kegiatan atau program peningkatan dan bantuan; apa yang digerakkan oleh Roh Kudus bukanlah kegiatan yang berlebihan, melainkan terutama perhatian yang menganggap orang lain "sebagai salah seorang dari diri kita sendiri” $(E G, 199)$. Yesus sendiri menginginkan para pewarta Injil yang menyampaikan kabar baik tak hanya dengan kata-kata, melainkan terutama melalui hidup yang diubah oleh kehadiran Allah $(E G, 259)$.

Roh Kudus adalah kekuatan dari dalam, yang menyerasikan hati para murid Kristus dengan hati Kristus. Ia menggerakkan mereka untuk mengasihi sesama manusia, seperti Yesus telah mengasihi mereka (bdk.Martasudjita, Pokok-Pokok Imam Gereja, 2013:211). Ketika Ia membungkuk untuk membasuh kaki para murid, dan terutama ketika Ia mengurbankan hidup-Nya bagi semua $(D C, 19)$.

Roh Kudus adalah juga kekuatan baru, yang mengubah hati persekutuan gerejawi, agar di dunia ini memberi kesaksian tentang kasih Bapa, yang mau membuat umat manusia dalam Putra-Nya menjadi satu keluarga. Semua tindakan Gereja, dan terutama perhatian kepada orang miskin, adalah ungkapan kasih, yang mengusahakan kesejahteraan seutuhnya manusia (Martasudjita, Pokok-Pokok Imam Gereja, 2013:211).

Dalam kerangka membuat Gereja hidup dalam pengaruh Allah yang merajainya, Roh kudus mempunyai peran penting membarui dan menyempurnakan Gereja dan karyanya.

"The Holy Spirit is the active, incarnate power of love by which human beings, their communities, and the world at large are healed, renewed, and brought to the fullness of perfections" (McBrien, The Church, 2008:4) 
Kasih yang kuasanya dituntun oleh Roh Kudus harus menjadi jiwa dari pengabdian yang dikembangkan Gereja dalam menanggapi penderitaan dan kekurangan materiil manusia (DC, 19; bdk. EN, 75). Roh Kuduslah yang sesungguhnya menggerakkan Gereja, sebagaimana Yesus, mendekat kepada orang-orang miskin (bdk. Luk.4:18-20).

\section{Solidaritas - Kasih - dan Belas Kasih}

Tiga hal ini, solidaritas, kasih dan belas kasih, merupakan hal dasariah dan komplementer dalam karya karitatif Gereja. Solidaritas merupakan bagian dari karya kasih, yang merupakan hal mendasar dalam tugas perutusan Gereja di dunia terutama dalam palayanan kepada orang miskin, sakit, kesepian, ditinggalkan ataupun mereka yang di penjara (Cahyadi, Gereja, 2010:133). Evangelii Gaudium menyatakan, solidaritas adalah reaksi spontan dari mereka yang mengetahui bahwa fungsi sosial harta milik dan tujuan universal harta benda adalah kenyataan yang mendahului kekayaan pribadi (bdk. Curran, The Moral, 2005:215).

Santo Vinsensius A Paulo, yang oleh Paus Benedictus XVI dalam Ensiklik Deus Caritas Est ditegaskan sebagai ikon dan sumber inspirasi karya kasih dan solidaritas kristiani, menyatakan:

"Si miskin tidak akan dapat mengampuni pemberian Anda, jika Anda tidak mencintai mereka" (Fuellenbach, Mewartakan, 2004:201).

Kasih merupakan juga dasar dari sikap Gereja memperhatikan orang miskin. Jika dasar ini hilang maka sikap memperhatikan orang miskin mudah jatuh menjadi sebuah akvitisme belaka yang melelahkan dan tanpa pengaruh yang signifikan bagi pembentukan 'masyarakat kontras' yang ditandai oleh kasih persaudaraan (bdk. Darmawijaya, Keterlibatan, 1991:63).

Bertemu dengan Allah yang penuh belas kasih yang ingin diikuti oleh Gereja merupakan suatu langkah besar dalam spiritualitas Gereja memperhatikan orang miskin. Dalam keterlibatan terhadap orang-orang miskin terciptalah suatu penemuan: orang menyadari kekuatan pendorong dalam keprihatinan Yesus terhadap kita, apa yang menggerakkan-Nya, dan 
apa yang merupakan inti semua perbuatan-Nya, yaitu belas kasih (lih. Fuellenbach, Mewartakan, 2004: 230).

Evangelii Gaudium menegaskan bahwa, kasih yang sejati selalu kontemplatif. Ia memungkinkan kita melayani orang lain bukan karena kebutuhan atau kesombongan, melainkan karena ia bagus melampaui penampilannya: "Cinta yang membuat kita merasakan orang lain menyenangkan mendorong kita memberi sesuatu kepadanya dengan cumacuma” (ST THOMAS AQUINAS, S.Th., II-II,q.27, a. 2.). Orang miskin, bilamana dicintai, "dihargai sebagai yang sangat bernilai," (ST THOMAS AQUINAS, S.Th., II-II,q.110, a.1.) inilah apa yang membuat pemihakkan sejati kepada orang-orang miskin berbeda dari ideologi lain, dari setiap upaya untuk mengeksploitasi orang-orang miskin demi kepentingan pribadi atau politiknya sendiri. Hanya berdasarkan kedekatan nyata dan tulus inilah kita dapat dengan tepat mendampingi orang-orang miskin di jalan pembebasan mereka. Dan bukankah pendekatan ini merupakan penyampaian Kabar Baik Kerajaan Allah yang paling luhur dan paling efektif? $(E G, 199)$. Kasih, pada prinsipnya, merupakan jiwa dari pengabdian yang dikembangkan Gereja untuk terus-menerus menanggapi penderitaan dan kekurangan materiil manusia $(D C, 19)$.

Pelayanan kasih, dengan demikian, adalah bagian tak terpisahkan dari jati diri kristiani (bdk. DC 25), sesuatu yang sejak awal hingga kini dan senantiasa selalu terus dihidupi dan diwujudkan (Cahyadi, Gereja, 2010:163). Pelayanan kasih kristiani semacam itu menjadi sebuah kesaksian nyata dari iman akan Kristus. Ia mempertegas apa yang dikatakan oleh Rasul paulus mengenai iman yang disertai dengan perbuatan. “... aku akan menunjukkan kepadamu, imanku dari perbuatan-perbuatanku.” (Yak 2:19).

\section{Mengkontemplasi Tuhan}

Kegiatan praktis pelayanan Gereja tetap kurang, bila di dalamnya tidak dirasakan kasih kepada manusia, yang dipupuk dalam perjumpaan dengan Kristus $(D C, 34)$. Gereja memperhatikan orang miskin, sejatinya 
adalah sebuah gerakan doa, yakni mengkontemplasi Tuhan. Starting point seruan apostolik Evangelii Gaudium menyatakan bahwa hal mendasar sukacita dari Injil itu, yang ini menegaskan spiritualitas karyanya, yakni menjumpai Yesus. "Sukacita Injil memenuhi hati dan hidup semua orang yang menjumpai Yesus" $(E G, 1)$.

Menjumpai Yesus harus ditemukan dalam segala yang dilakukan, terlebih dalam karya terhadap orang miskin. Semangat mengkontemplasi Tuhan dalam segala karya, terutama dalam karya kerasulan (bdk. Barry, The Jesuit Way, 2006: 62), yang diwariskan oleh Ignatius Loyola, sangat kental cita rasanya dalam Evangelii Gaudium. Semangat rohani Santo Ignasius Loyola ini tidak eksklusif milik para Jesuit. Semangat mengontemplasi Tuhan menjadi warisan rohani bagi spiritualitas Gereja semesta.

Gereja sungguh diperkaya oleh aneka warisan rohani para kudusnyamereka yang telah teruji dan menjadi rujukan praktis- dalam karya kasih bagi orang miskin. Santo Vinsensius A Paulo, yang dilihat oleh Paus Yohanes Paulus I sebagai gigante della carita, menemukan jalan rohani yang sama:

"melayani orang miskin tidak hanya berarti meneladani Kristus, melainkan juga melayani Kristus sendiri” (Roman, Santo Vinsensius, 1991:52).

Bila kita melayani orang miskin kita melayani Kristus sendiri. Santa Teresa dari Kalkuta, pelaku karya karitatif paling ternama di zaman kita ini, juga menerima karunia rohani yang sama. Ia mampu menemukan Dia yang tersembunyi dalam wajah yang tersamar pada wajah orang miskin dan menderita (Cahyadi, Jalan Pelayanan Ibu Teresa, 2003: 58)

Gereja, dalam semangat direksi rohani dari para kudusnya, menemukan makna dasariah karya karitatif. Mengkontemplasi Tuhan ditemukan dalam jalan memperhatikan orang miskin dan lemah. Sebab, kasih yang sejati adalah selalu kontemplatif $(E G, 199)$. 


\section{Sikap Berpihak kepada Kaum Miskin: Perubahan Nilai}

Ada dua unsur pokok yang mendasar -bagian dalam Teologi Pembebasandalam perjuangan bersama orang miskin, (Fuellenbach, Mewartakan, 2004: 237238) yakni: Pertama, sikap berpihak pada kaum miskin merupakan cara yang tepat untuk mengikuti Yesus di zaman ini. Kedua, wawasan bahwa status kita dalam kondisi masyarakat bukan hanya ditentukan oleh cara berpikir dan cara kita menerima realitas, tetapi juga cara kita memahami Injil $(E G, 181)$ dan menerimanya sebagai sabda Tuhan.

Dalam melihat realitas ini, para teolog pembebasan mengisyaratkan adanya fenomena "ketidakpedulian terhadap hal-hal tertentu" - selective in attention - (bdk. $E G, 201)$. Dalam hal ini, kita mengelak dari fakta tertentu yang sekiranya mengancam status dan cara hidup kita yang telah mapan dan nyaman. Banyak fakta yang benar-benar merusak terjadi di sekitar kita, tetapi kita tidak mau peduli karena tidak merugikan kita. Kecenderungan untuk tidak peduli terhadap hal-hal yang merugikan orang lain muncul bersama pengaruh-pengaruh dosa asal lainnya, seperti: keinginan untuk menguasai, memiliki, atau bahkan menindas. Fenomena ini lembut dan sering tanpa kita rasakan telah merasuki diri kita.

Sikap berpihak kepada orang miskin, tindakan palayanan kepada orang miskin bertentangan dengan semua kecenderungan dosa itu. Perhatian kepada orang miskin membina kita bertumbuh dalam kualitas kasih seperti disintesakan dalam Perjanjian Baru: "Kasihilah sungguh-sungguh seorang akan yang lain, sebab kasih menutupi banyak sekali dosa (1 Ptr 4:8). Kebenaran ini sangat mempengaruhi cara berpikir para Bapa Gereja dan membantu menciptakan perlawanan profetis, sebagai budaya tandingan menghadapi pengaruh hedonisme egosentris dari mereka yang tidak beriman $(E G, 193)$.

\section{Kesaksian Profetis}

Bagi Gereja, keberpihakkan kepada orang miskin pada pokoknya adalah kategori teologis dari pada kategori budaya, sosiologis, politis atau filosofis. Allah menunjukkan kepada kaum miskin kemurahan hati yang pertama". Preferensi Ilahi ini memiliki konsekuensi bagi hidup beriman semua umat Kristiani, karena kita dipanggil untuk memiliki "pikiran... yang terdapat juga dalam Yesus Kristus (Flp 
2:5). Gereja telah memihak orang miskin dipahami sebagai "bentuk khusus prioritas dalam mengamalkan cinta kasih Kristiani (bdk. Curran, The Moral, 2005: 214). Dan pemihakan terhadap kaum miskin, seperti diajarkan oleh Benediktus XVI, "tersirat dalam iman Kristiani kita akan Allah yang menjadi miskin bagi kita, agar kita menjadi kaya karena kemiskinan-Nya" (EG, 198).

Dalam pandangan alkitabiah, perhatian kita terhadap kaum miskin merupakan cara kita berdialog dengan semua bangsa yang mempunyai kehendak baik. Dan kehendak Allah untuk mengadakan transformasi dunia ini ialah dengan membangun masyarakat kontras atau alternatif. Orang bisa memasuki masyarakat ini dengan mengikuti Yesus; memiliki pikiran yang terdapat dalam Yesus Kristus $(E G, 198)$. Tidak ada jalan murah yang dipisahkan dari iman. Seorang yang menafsirkan kitab suci mengenai pembebasan kaum miskin sebagai cara untuk menolong kaum miskin, tetapi tanpa iman dan tanpa transformasi dunia dalam diri masyarakat yang beriman itu, berarti menyalahgunakan teks dan tidak melaksanakan keadilan. Membebaskan kaum miskin hanya bisa dalam iman yang mengubah seluruh sikap kehidupan. Orang harus terbuka akan karya Roh Kudus yang ikut memperhatikan kaum miskin. Dengan demikian Allah sendiri akan berkarya dalam sejarah, berkat kerjasama manusia (Darmawijaya, Keterlibatan, 1991:82).

Karya karitatif kristiani kepada orang miskin bukan alat perubahan dunia yang dikendalikan secara ideologis dan tidak mengabdi strategi dunia, melainkan sekarang dan di sini merupakan sarana penghadiran kasih, yang selalu dibutuhkan manusia (bdk. DC, 31). Karya kasih kristiani kepada orang miskin yang semacam ini, dari dirinya sendiri menjadi suatu kesaksian profetis bahwa Tuhan yang ia imani dan ikuti adalah Tuhan yang hidup dalam GerejaNya lewat sentuhan tindakan kasih. Dalam konteks panggilan Gereja keluar (ad extra), kesaksian profetis menyatakan amanat bahwa kita, pengikut Yesus, diutus mempermaklumkan kerajaan kasih sayang Allah ke dalam masyarakat serta menghadirkannya, secara konkret hal itu kita wujudkan dalam pelayanan kepada orang-orang miskin (bdk. Suseno, Menjadi Saksi Kristus, 2008: 45). 


\section{Gereja Memperhatikan Orang Miskin sebagai Revelasi dan Kontemplasi Substansi evangelium}

Evangelium sesungguhnya bermakna sangat indah. Kata evangelium secara substantif menunjuk pada pribadi Yesus. Istilah evangelium ini tampil dalam kosakata para kaisar Romawi yang memahami diri mereka sebagai tuan, penyelamat dan penebus dunia. Amanat yang dikeluarkan seorang kaisar dalam bahasa Latin disebut evangelium, tidak peduli apakah isinya benar-benar menggembirakan dan menyukakan atau tidak. Gagasannya adalah bahwa apa yang datang dari seorang kaisar adalah sebuah amanat yang menyelamatkan, artinya bukan sekedar sepotong berita melainkan sebuah perubahan dunia ke arah yang lebih baik.

Ketika para penginjil memakai kata ini, dan karenanya menjadi sebutan umum untuk tulisan-tulisan mereka, mereka bermaksud memberitahu kita hal ini: Apa yang diklaim secara tidak sah oleh para kaisar, yang berlagak bagai dewa, benar-benar terjadi di sini - sebuah amanat yang dipenuhi dengan kewibawaan yang paripurna, sebuah amanat yang bukan melulu "asal omong" melainkan kenyataan. Menurut kosakata teori linguistik kontemporer, kita bisa mengatakan bahwa evangelium, Injil, bukan melulu ujaran informatif, melainkan terutama ujaran performatif-bukan melulu menyampaikan informasi melainkan terutama tindakan, kekuatan ampuh dan berdaya guna yang masuk ke dunia untuk menyelamatkan serta membarui. Markus berbicara tentang "Injil Allah" dengan maksud bukan para kaisar itulah yang dapat menyelamatkan dunia, melainkan Allah. Dan di sinilah firman Allah itu, yang sekaligus merupakan perkataan dan perbuatan, tampil; di sinilah apa yang sekadar ditegaskan para kaisar itu tanpa sungguh-sungguh melaksanakannya benar-benar berlangsung. Karena di sinilah Tuhan yang sesungguhnya atas dunia-Allah yang hidup-bertindak (Ratzinger, Yesus, 2010: 45-46).

Gereja memperhatikan orang miskin, dengan demikian, sungguh merupakan suatu bentuk revelasi substansi evangelium itu sendiri. Gereja memperhatikan orang miskin sejatinya menyingkapkan pertemuan personalnya dengan Tuhan. Gereja memperhatikan orang miskin sama artinya dengan Gereja menjumpai Tuhan; Gereja mengkontemplasi Tuhannya. Gereja memperhatikan orang miskin memaksudkan 
pula bahwa Gereja sebagai tubuh mistik menemukan senantiasa kesatuan dirinya dengan Kristus, sang kepalanya.

Selain itu, evengelisasi yang sungguh baru dari semangat Evangelii Gaudium ini merupakan undangan untuk mengakui daya penyelamatan yang bekerja dalam hidup orang miskin dan untuk menaruh mereka di pusat jalan peziarahan Gereja (bdk. $E G$, 198).

Sebagai mempelai Kristus, Gereja dipanggil untuk menemukan Kristus di dalam diri orang miskin, untuk meminjam suara kita bagi perkara mereka, tetapi juga menjadi sahabat mereka, mendengarkan mereka, memahami mereka dan menerima hikmat tersembunyi yang ingin disampaikan Allah kepada kita melalui mereka (bdk. $E G, 198)$.

Yesus merevelasi diri-Nya melalui orang miskin. Ia mengidenitifikasi diri-Nya melalui mereka: ..."they represent for you the person of Our Lord, who said: "Whatever you do for one of these, the least of my brethren, I will consider it as done to me" (Maloney, The Way of Vincent De Paul, 1992: 26). Orang miskin mesti kita layani dengan respek dan sikap devotif. Karena orang miskin, menurut Evangelii Gaudium, memiliki banyak hal untuk diajarkan kepada kita. "Mereka tidak hanya berbagi dalam sensus fidei, tetapi dalam kesulitan-kesulitan mereka, mereka mengenal Kristus yang menderita" (EG, 198). Orang miskin sungguh menjadi tuan dan guru kita. Mereka juga memberikan kepada kita pewartaan Kabar Baik (bdk. EG, 198).

Orang Miskin, dimana Yesus merevelasi diri, sejatinya telah membawa suatu transformasi nilai dalam hidup kita. Yesus yang hardir dalam diri mereka sunguh manjadi evangelium - Sang Penyelamat - yang performatif pada hidup kita (bdk. Ratzinger, Yesus, 2010:46).

Peristiwa menjumpai Tuhan dalam diri orang miskin sungguh merupakan suatu sukacita sejati. Sebab, sukacita memenuhi hati dan hidup kita sebagai murid-murid Kristus karena kita akhirnya menjumpai Yesus $(E G, 1)$. Dari pilihan karya memperhatikan orang miskin, Gereja menemukan bahwa sukacita yang menjadi sasaran utama dari maksud seruan apostolik Evangelii Gaudium ini menjadi beroleh kepenuhan. 


\section{Belajar dari Maria Bunda Evangelisasi}

Marilah akhirnya kita memandang kepada Maria. Gereja tidak bisa meninggalkan Maria, bila hendak mendekat kepada Sang Putera. Maria, dialah sesungguhnya orang yang selalu memandang wajah Tuhan. Dia tabah dan setia berada di kaki salib Putranya. Ia memandang Sang Putra yang tersalib. Ia mengkontemplasi wajah penderitaan sejati, penuh kemiskinan: puteranya wafat di salib. Tidak hanya berhenti di situ. Maria telah membawa Gereja memandang kerahiman Allah $(E G, 285)$. Maria mengantar Gereja memandang Yesus; yang menyatakan perbuatan cinta sehabis-habisnya demi keselamatan manusia. Maria selalu menjadi prototipe iman kita dalam direksi spiritual untuk mengkontemplasi Yesus. Oleh karena orang miskin adalah representasi diri Allah, maka kita diundang untuk memandang Tuhan dalam aksi solidaritas dengan kaum miskin. Solidaritas mengingatkan kita akan kenyataan interdependensi kita sebagai masyarakat manusia (bdk. Curran, The Moral, 2005: 213).

Maria, Perawan dan Ibu, menunjukkan kepada kita, apa arti kasih dan dari mana ia menimba asal-usulnya, serta kekuatannya yang selalu dibarui. Kepadanya kita mempercayakan Gereja, perutusannya dalam pelayanan kasih, terlebih pelayanan kepada orang miskin (bdk. $D C, 42$ ). Allah sendiri membawa kita kepada Maria, Karena Dia tidak meninginkan kita berjalan tanpa seorang ibu, dan umat membaca dalam citra keibuan Maria ini semua misteri Injil; penyingkapan diri Allah dalam sejarah hidup manusia, terutama melalui kehadiran orang miskin di sekitar kita (bdk. EG, 285).

Kita pun sadar bahwa dinamika belas kasih, keadilan dan kelembutan, kontemplasi dan perjalanan menuju orang lain adalah apa yang membuat Maria menjadi teladan Gereja untuk berevangelisasi- upaya terus menerus untuk membuat Kristus yang penuh belas kasih hadir dan memberi pengaruh pada hidup manusia-. Gereja, sakramen Yesus Kristus, kemudian, dapat menjadi rumah bagi banyak orang, seorang ibu untuk semua bangsa, dan agar memungkinkan kelahiran dunia baru (bdk. $E G, 285)$. 


\section{Kesimpulan}

Gereja memperhatikan orang miskin adalah sebuah kategori teologis. Gerakan pastoral, dengan pilihan berpihak pada orang miskin harus mengedepankan semangat: dijiwai oleh Roh Kudus, mendasarkan sikap solider, pelayanan yang penuh kasih, berbelas kasih dan tentu penuh pengorbanan juga. Perhatian kepada orang miskin membina kita bertumbuh dalam kualitas kasih.

Allah sungguh memiliki hati yang khusus terhadap orang miskin. Sehingga Ia memilih pola realitas hidup mereka; Ia merepresentasikan diri-Nya dalam diri mereka. Dan, Gereja harus menangkap misteri atau penyingkapan diri Allah yang tersamar namun nyata dalam diri orang miskin itu. Sikap iman dan kesadaran kritis harus terus dibina supaya kita mampu menangkap dan memandang realitas revelasi diri Allah yang Ia kerjakan melalui orang miskin itu. Allah kita adalah Tuhan kehidupan yang bergerak aktif di dalam Roh-Nya untuk membawa pengaruh transformasi pada hidup kita. Orang miskin adalah Tuan (lord) dan guru (master) kita yang mengajar kita banyak hal untuk menangkap misteri Tuhan, berbagi dalam sensus fidei, dalam kesulitan-kesulitan mereka, dan terutama dalam pengenalan Kristus yang menderita. Kita, kemudian, harus mengakui daya penyelamat yang bekerja dalam hidup mereka, untuk memperhitungkan mereka dan untuk menaruh mereka di pusat peziarahan Gereja.

Didalam kesatuan dengan Bunda Maria sebagai prototipe iman, Gereja akan mampu dan tetap setia mengkontemplasi Tuhan -wajah yang bahagia maupun wajah yang menderita - yang tersamar dalam diri orang miskin.

Gereja akan memberi sumbangan yang berati di zaman ini apabila kita dapat menerapkan nilai-nilai Injili yang sesungguhnya dan apabila kita mampu melaksanakan kesepakatan hati kita untuk mengikuti Kristus dan berpihak kepada kaum miskin; kaum dimana Tuhan merevelasi diri. Orang miskin adalah sebuah realitas sesungguhnya dimana kita dapat memandang wajah Tuhan; menjumpai penyingkapan diri-Nya. Pada akhirnya mengkontemplasi wajah Tuhan secara demikian ini menjadi alasan kebahagiaan dan sukacita yang memenuhi hati dan hidup beriman kita. Sebab manusia, siapapun dia, dari kodratnya adalah makhluk yang dicipta secitra dengan wajah Tuhannya. 


\section{Daftar Pustaka}

Barry, William A. SJ dan Robert G. Doherty, SJ. The Jesuit Way - Kontemplasi dalam Aksi. Yogyakarta: Kanisius, 2006.

Cahyadi, T.Krispurwana. Gereja dan Pelayan Kasih. Yogyakarta: Kanisius, 2010.

Cahyadi, T.Krispurwana. Jalan Pelayanan Ibu Teresa. Jakarta: Obor, 2003.

Curran, Charles E. The Moral Theology of Pope John Paul II. Washington, D.C.: Georgetown UniversityPress, 2005.

Darmawijaya, ST. Keterlibatan Allah terhadap Kaum Miskin- dalam Persepktif Teologi Biblis. Yogyakarta: Kanisius, 1991.

Dokumen Deus Caritas Est. Jakarta: Dokpen KWI, 2007.

Dokumen Evangelii Gaudium. Jakarta: Dokpen KWI, 2014.

Dokumen Evangelii Nuntiandi. Jakarta: Dokpen KWI, 2011.

Dokumen Konsili Vatikan II. Jakarta: Dokpen KWI, 2008.

Fuellenbach, John. Mewartakan Kerajaan Allah. Ende: Nusa Indah, 2004,

Maloney, Robert P. The Way of Vincent De Paul - A Contemporary Spirituality in the Service of the Poor. USA: New City Press, 1992.

Martasudjita, Emanuel. Pokok-Pokok Iman Gereja - Pendalaman Teologis Syahadat. Yogyakarta: Kanisius, 2013.

McBrien, Richard P. The Chuch: The Evolution of Catholicism, New York: Harper Collins Publishers, 2008.

O’Collins, Gerald SJ. dan Edward G. Farrugia, SJ. Kamus Teologi. Yogyakarta: Kanisius, 1996.

Ratzinger, Joseph. Yesus dari Nazaret, Jakarta: Gramedia, 2010.

Roman, J.M. Santo Vinsensius De Paul- Hidup Panggilan dan Spiritualitasnya. Malang: Pustaka Vincentiana, 1991.

Suseno, Magnis. Menjadi Saksi Kristus di Tengah Masyarakat Majemuk.Jakarta: Obor, 2008. 